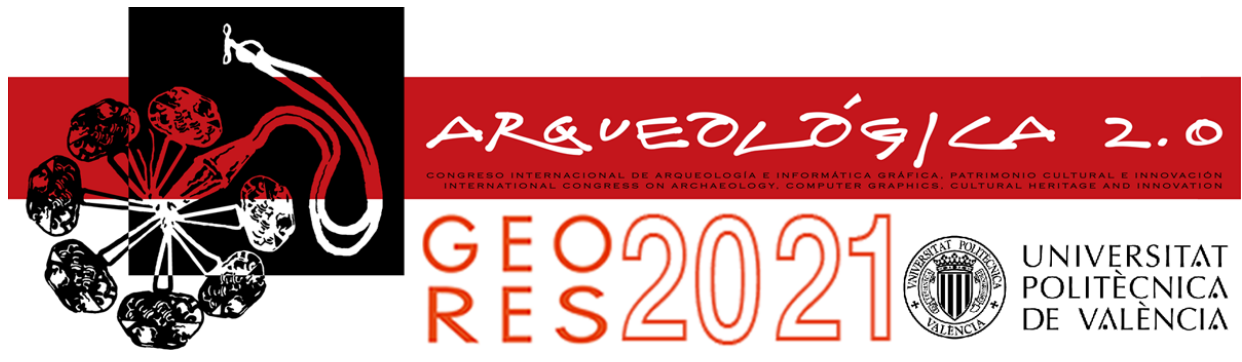

Proceedings of the joint international event $9^{\text {th }}$ ARQUEOLÓGICA

$2.0 \& 3^{\text {rd }}$ GEORES

Valencia (Spain).

26-28 April 2021

\title{
STUDY ON QUALITY IN 3D DIGITISATION OF TANGIBLE CULTURAL HERITAGE
}

\author{
Douglas Pritcharda, ${ }^{*}$, Thomas Rigauts ${ }^{a}$, Francesco Ripantia, Marinos loannides ${ }^{a}$, Raffaella \\ Brumana $^{\text {b }}$, Robert Davies ${ }^{a}$, Eleanna Avouria, Harriet Cliffena, Nenad Joncic ${ }^{a}$, Giulia Ostia, Marina \\ Toumpouria

\begin{abstract}
${ }^{a}$ Digital Heritage Research Laboratory, Department of Electrical Engineering, Computer Engineering and Informatics, Cyprus University of Technology, Arch. Kyprianou 31, CY 3036 Limassol, Cyprus. douglas.pritchard@cut.ac.cy; thomas.rigauts@cut.ac.cy; francesco.ripanti@cut.ac.cy; marinos.ioannides@cut.ac.cy; robert.davies@cut.ac.cy; eleni.avouri@cut.ac.cy; harriet.cliffen@cut.ac.cy;
\end{abstract} \\ nenad.joncic@cut.ac.cy; giulia.osti@cut.ac.cy; marina.toumpouri@cut.ac.cy \\ b Dipartimento Architettura, Ingegneria delle Costruzioni e Ambiente Costruito (ABC), Politecnico di Milano, Via Ponzio 31, 20133 Milan,
} Italy. raffaella.brumana@polimi.it

\begin{abstract}
:
Following the implementation of the Virtual Multimodal Museum (ViMM) project, which finished in March 2019, the European Commission issued a Declaration on Cooperation on Advancing Digitisation of Cultural Heritage during the Digital Day in April 2019. One year later, in April 2020, the European Commission (EC) launched a commercial call for tenders to develop a Study on quality in 3D digitisation of tangible cultural heritage (the study). The tender theme is to acknowledge the increasing demand for internationally recognised standards for the holistic 3D documentation of Europe's rich cultural heritage $(\mathrm{CH})$ and address the lack of standards. The study aims to map parameters, formats, standards, benchmarks, methodologies, and guidelines relating to 3D digitisation of tangible cultural heritage, the different potential purposes or uses, by type of tangible cultural heritage, and the degree of complexity of tangible cultural heritage. A team of researchers at the Cyprus University of Technology (CUT) leads a consortium of partners from industry and academia across Europe to conduct this unique study. This work in progress paper introduces the research's objectives and methodology and presents some of its first results.
\end{abstract}

Keywords: tangible cultural heritage, documentation, 3D digitisation, international documentation standards, digital heritage

\section{Introduction}

The digital documentation and virtual representation of artefacts, monuments, and sites are essential for the conservation, management, scientific documentation, and cultural heritage analysis. At present, there are a vast array of technologies, recording methods, software solutions and post-processing techniques to address this issue. Despite the ever-increasing demand for these systems and procedures, there are few internationally recognised standards or methodologies for 'the comprehensive, holistic 3D documentation of European cultural heritage assets.' As the value of 3D digitisation technologies in cultural heritage is growing steadily, the need for standards becomes ever more urgent.

In 2019, 27 Member States of the European Union had committed to the importance of these digital technologies by signing the Declaration of Cooperation on advancing the digitisation of cultural heritage on Digital Day (April 2019). By doing so, they endorsed the call for common standards, methodologies and guidelines for the holistic 3D documentation of European Cultural Heritage (European Commission, 2019).

In April 2020, the European Commission launched a call for tenders to carry out for the first time a Study on quality in 3D digitisation of tangible cultural heritage (VIGIE 2020/654). The purpose of the call is to map parameters, formats, standards, benchmarks, methodologies and guidelines, relating to the $3 \mathrm{D}$ digitisation of tangible cultural heritage. Addressing the different potential purposes or uses, by type of tangible cultural heritage, and the degree of complexity of tangible cultural heritage (European Commission, 2020b).

As illustrated in Figure 1, the Cyprus University of Technology (2020a), which holds the UNESCO and ERA Chairs on Digital Cultural Heritage, is leading a consortium of partners from the industry and academia across Europe to conduct this unique study (European Commission, 2020c). 


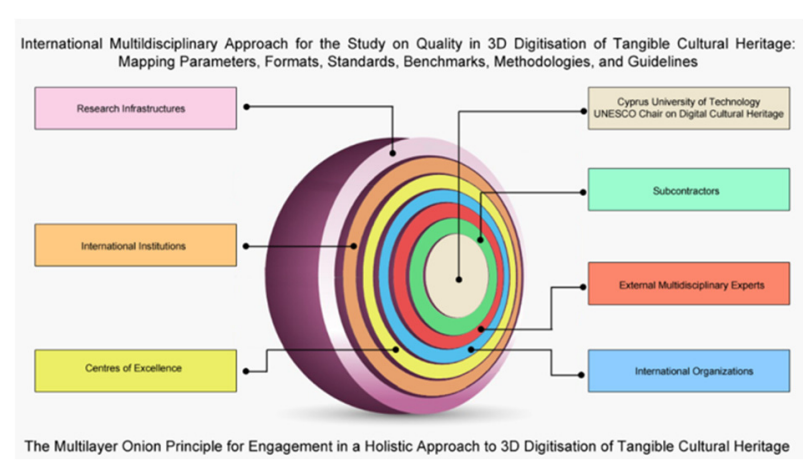

Figure 1: Consortium of experts and external partners for the Study.

\section{The study}

The ongoing VIGIE 2020/654 Study draws upon existing analysis and information sources, comprising a large amount of prior knowledge represented by the in-house team, supplemented by preliminary research. These emanate from a variety of relevant sources, including literature reviews, scientific publications and technological surveys, and information from scientific organisations, cultural heritage institutions, SME's, industry, and government. Previous efforts to develop guidelines for cultural heritage documentation include Historic England (2017; 2018), Historic Environment Scotland (2018) and the European Commission (2020a). The Study also incorporates a wide range of External Experts, which forms part of the study team and will be extended through the subsequent investigation throughout the Study (see Fig. 1).

The digital representation of cultural heritage objects, architectural structures and environments is an essential tool for analysis, conservation, interpretation and exhibition. However, selecting the most effective recording technology and efficient production workflow for the $3 \mathrm{D}$ digitisation of tangible cultural heritage is a complicated procedure requiring careful consideration.

As identified by the European Commission there is no generally accepted framework for specifying the level of detail and accuracy in $\mathrm{CH}$ digitisation. Documentation projects are typically determined on a case-by-case basis, using the many available methods, and often require significant interdisciplinary cooperation. In addition to the cost of hardware and associated software, there is also a considerable investment in knowledgeable staff and time dedicated to specialised training (European Commission 2020).

The purpose of the VIGIE 2020/654 Study is to investigate the parameters, formats, standards, benchmarks, methodologies and guidelines, relating to the 3D digitisation of tangible cultural heritage. The Study is intended to be exceptionally comprehensive and will address topics such as:

- recording hardware, for example, LiDAR scanning, photogrammetry etc.;

- types of data, formats, standards, benchmarks, methodologies and guidelines;

- defined digitisation process stages and attention to the importance of a structured approach to managing $3 \mathrm{D}$ digitisation projects;
- quality parameters;

- degrees of complexity;

- purposes, audiences and use;

- formats, standards, benchmarks, methodologies and guidelines;

- equipment;

- $\quad$ past or ongoing digitisation projects and 3D models and data sets that can serve as benchmarks and future technological advances.

The Study's unique idea is to develop a framework of standardised best-practices and methods concerning the recording, processing, production, long-term preservation and reuse of $3 \mathrm{D}$ objects and associated metadata. According to the terms of the original EC tender, the Study addresses two broad areas of tangible cultural heritage. One refers to 'immovable' tangible cultural heritage including buildings, monuments, sites, and maritime archaeology. The other looks at 'movable' tangible cultural heritage, such as museum objects, archaeological finds and other artefacts.

Of particular importance in the 3D documentation process is that the VIGIE 2020/654 Study must address surface or geometrical complexity as a general classification. For example, "low complexity refers to tangible cultural heritage with few and straightforward features. At the other end, tangible cultural heritage with a very high degree of complexity is very detailed and has a large number of complicated features that require considerably more effort to capture."

Defining the degree of complexity in a 3D documentation project is essential as it typically prescribes the necessary production effort. Complexity in architecture or sites can be determined by various factors such as geometrical exuberance, height, accessibility and surface quality. For example, a High Gothic church's documentation such as the Cologne Cathedral would take considerably longer than an office building constructed in the 1950s, even if they have the same dimensional footprint.

\section{Preliminary results}

\subsection{Complexity and quality}

As cultural heritage is highly diverse, and the resulting 3D models are often quite complex, it can be challenging to achieve a certain level of quality in 3D digitisation. There are many parameters involved at the various stages of the $3 \mathrm{D}$ documentation process. They can vary by the purpose of the Study, user, equipment used and methodology, as illustrated in Figure 2.

The term quality is highly subjective and easily open to misinterpretation. Formulating a clear, precise definition concerning $3 \mathrm{D}$ digitisation is a challenge. The study's initial data quality indicators include accuracy, precision, resolution, and the acceptable margin of data error. Further considerations, as expressed in a recent report by the Expert Group on Digital Cultural Heritage and Europeana (2020), are also taken into consideration in this Study: "Quality in 3D digitisation of cultural heritage is not only about capture accuracy and resolution, but also about other key aspects such as historical accuracy, range of data and metadata generated and collected, and fitness for purpose." 


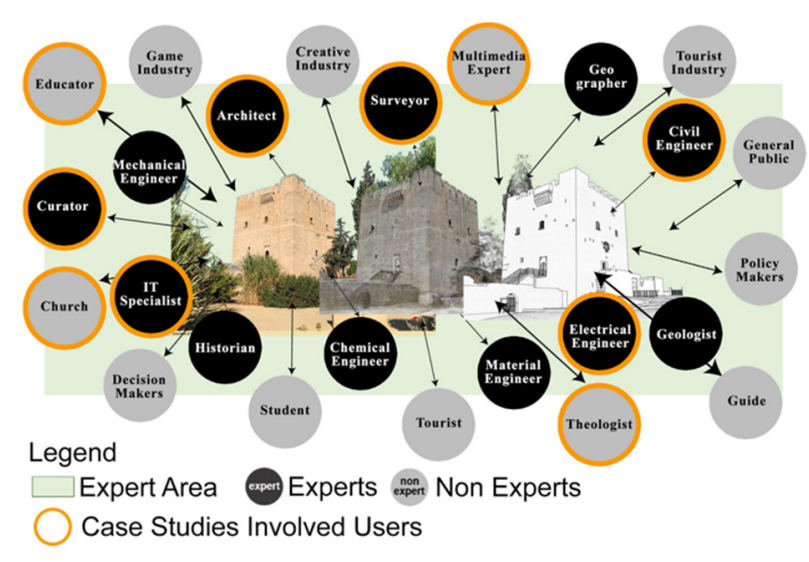

Figure 2: Cultural Heritage Documentation according to the needs of multidisciplinary users.

Another factor to consider is the degree of complexity of the cultural heritage object to be digitised. The complexity of an artefact or building can refer to its size, geometry, interior/exterior, surface and many other parameters that may impact the challenges in capturing the object in $3 D$, as illustrated in Figure 3.

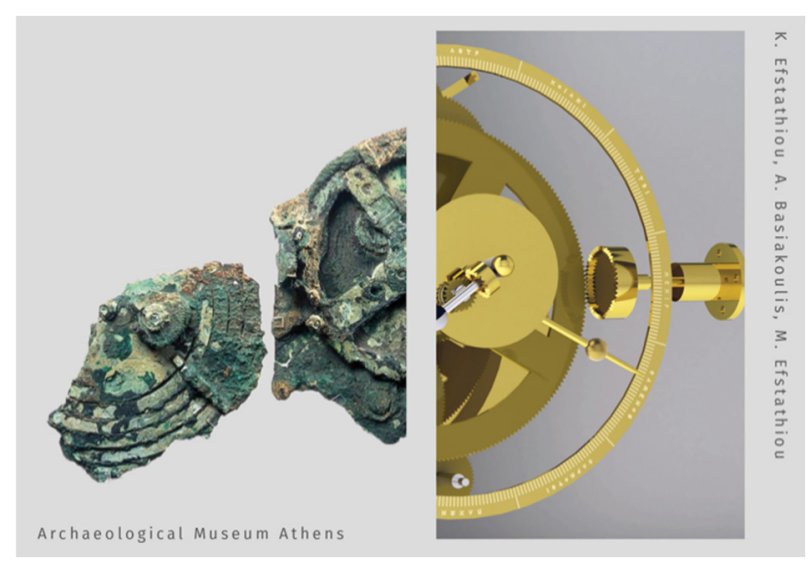

Figure 3: Complexity of an artefact, the Antikythera Mechanism, (interior/exterior).

Establishing a definition of the degrees of complexity of tangible cultural heritage and identifying the parameters that determine quality in 3D digitisation of cultural heritage has been the Study's initial focus. CUT has consulted with a consortium of experts to provide input on these questions during the Study's first months. The budget of a documentation project, physical and environmental conditions, technology, and equipment influenced complexity and quality, as highlighted by these experts. The consortium is now compiling the information into a comprehensive report on the technical parameters that determine the quality and complexity of $3 \mathrm{D}$ digitisation.

\subsection{D quality models and HBIM opportunities}

$3 \mathrm{D}$ models have the opportunity to become core digital gears leveraging knowledge, interpretation and understanding. They are tools through which it is possible to decode cultural heritage's complexity, extract contents, and integrate them within multidisciplinary processes.

Complexity is related to several issues which need to be taken into account with an overall approach: methods of surveying and digitisation require to be addressed within a holistic framework, where models are related to information. Despite the BIM limitations when applied to the HBIM, the world of Heritage Building Information Modelling could help orient 3D quality models (Brumana, Banfi, Cantini, Previtali, \& Della Torre, 2019; Brumana et al., 2018).

$3 \mathrm{D}$ quality models are required to support the digitisation of state of the art (SofA) as resulting from:

- $\quad$ past stratified layers across the centuries and transformation phases with its materials, techniques and geometry;

- the fragility coming from the state of decay and deformation occurred throughout the centuries. Conditions that can be detected through the geometric analysis together with the knowledge of the processes involving the materials and their construction techniques, with the help of NonDestructive Techniques and other diagnostics;

- fragility as impacted by current hazards and pressures (i.e., climate change, earthquakes, flooding, flash water bombs, landslide, hydrogeological risks) within the context of the built environment.

The common element is that the geometry cannot be considered a standalone issue, but requires integration with the materials. These materials are intended to extend the understanding of construction techniques within a multiscale concept.

The scale concept inherited from the cartographic domain in surveying specifications can be applied to the models to help define the need and drive transparent data sharing. One parameter for determining the quality of 3D models is dimensional accuracy, which encompasses tolerance and details incorporated. The richness of the information collected in the digitisation process represents the second pillar of the knowledge process.

The concept of HBIM Level of Development (the combination of the Level of Geometry and Level of Detail) can be integrated to enrich the quality of $3 D$ models during the phases of the modelling and preservation process. To this aim, a new definition of LOD is proposed by the contributors to the VIGIE project, which differs from the BIM building construction process logic. This can vary from LOD100 up to LOD600 depending on the information embedded in the 3D BIM model.

Therefore, the quality of $3 \mathrm{D}$ models needs to match the following requirements:

a) to reflect the exact geometry and any other anomalies available on the surface of the artefact/monument (such as corrosion, cracks, etc.);

b) to support information enrichment with materials properties and construction techniques analysis;

c) to support the assessment and the data interpretation (structural behaviour);

d) to drive the preservation plans starting from understanding and interpreting state of the art up to supporting the design and decision-making process; 
e) to prevent future damages fostering planned preservation (Long Life Cycle Management);

f) to deploy knowledge transfer of enriched models among different operators;

g) to promote the use and re-use for dissemination purposes (MR/VR/AR).

\subsection{Awareness and Dissemination}

The Study was presented to a broad audience of heritage professionals, students and culture enthusiasts at the 8th International EuroMed Conference on Digital Cultural Heritage (Cyprus, 2-5 November 2020 , www.euromed2020.eu). It was organised online this year due to the global pandemic, it attracted over one thousand participants from more than seventy different countries (EuroMed, 2020).

The first workshop of EuroMed 2020 (2 November 2020), organised by the Digital Heritage Research lab and was specifically dedicated to the Study, featuring speakers from all subcontracted expert organisations and institutions, such as:

- Historic Environment Scotland.

- Zoller \& Fröhlich GmbH.

- National Technical University of Athens.

- ArcTron 3D GmbH.

- $\quad$ Aristotle University of Thessaloniki.

- Bene Construere.

- Politecnico di Milano.

- Time Machine Organisation.

- ICOMOS.

The workshop also invited speakers from beyond the network of experts involved in the Study, including:

- Getty Research Institute.

- Global Digital Heritage.

- Smithsonian Institution.

- IIIF 3D Community Group.

- Cambridge University.

- Mnemoscene.

- Duke University.

- Cultural Heritage Imaging.

- Uppsala University.

The keynote speakers were all asked to present their experiences on the different degrees of tangible cultural heritage from the 3D documentation process and the parameters that determine quality in $3 D$ digitisation of tangible cultural heritage. In this way, their presentations directly contributed to the requirements of the Study. The workshop outcomes are currently being processed and will feature in the Study's final output report in June 2021.

\subsection{Online Survey}

The main objective of the questionnaire entitled "Survey on quality in the digitisation of tangible cultural heritage" is to support the study by collecting from multidisciplinary experts in the domain of digital acquisition data about the use of acquisition technologies, metadata, paradata, and the definitions of quality and complexity for 3D (Cyprus University of Technology, 2020b). The survey is currently running digitally on the platform LimeSurvey, and the plan is to collect responses in the period $21 / 10-31 / 12 / 2020$. It is advertised through the DHRLab social network profiles (Facebook, Instagram) and the consortium.

The questionnaire consists of 40 questions, grouped into four sections:

- General information and demographics.

- Overview of the used technologies - where data about the most popular acquisition technologies are collected.

- Description of the project.

- Final questions.

The questionnaire requires a minimum of 15 minutes to be filled and is also scalable: respondents have the option to describe up to three digitisation projects, answering the same set of questions three times.

The demographic section asked respondents about, among other things, provenience, professional background, years of experience and affiliation to relevant organisations. In the overview of the used technologies section, data about the most popular acquisition technologies are collected. The section regarding the description of the project requires each respondent for information on a successful digitisation project on immovable and movable objects and for specifics about the used technology, metadata, paradata, limitations and problems.

The data is intended to enrich the information collected from the core subcontractors about quality and complexity and support the study in showcasing the best-practice projects in the digitisation domain. More than 200 completed responses have been collected from more than 40 countries worldwide after the first month.

As indicated in Figures 4, 5, 6 and 7, the data collected so far comes from a wide range of experts in digitising both monuments and sites and museum objects worldwide and will be processed in early 2021.

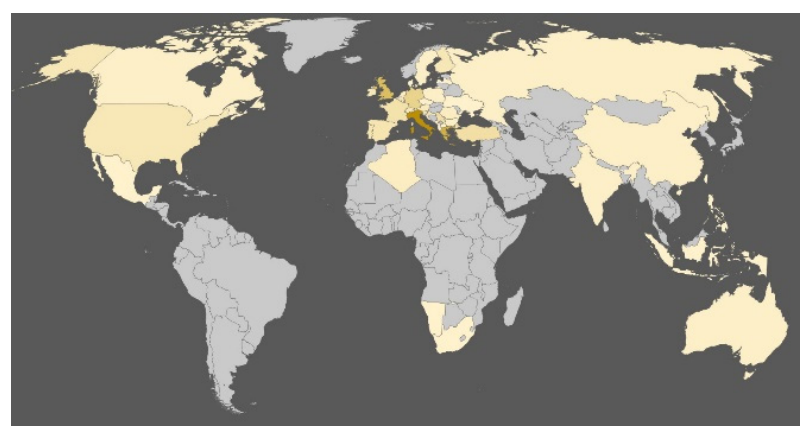

Figure 4: The map shows the geographical provenance of the respondents $(n=235)$. 


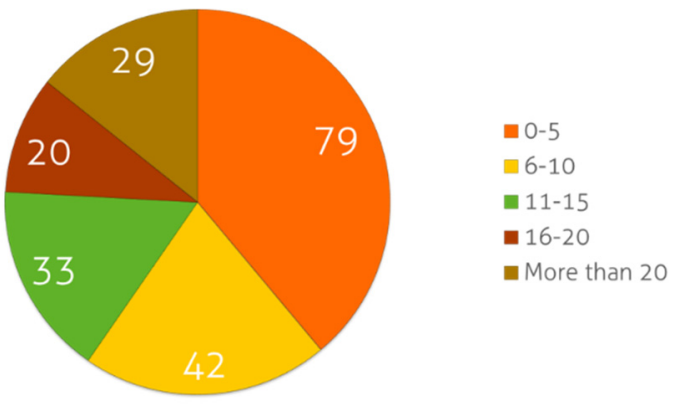

Figure 5: The graph reports the answers to the question "How many years of experience do you have in the digitisation area?" $(n=203)$.

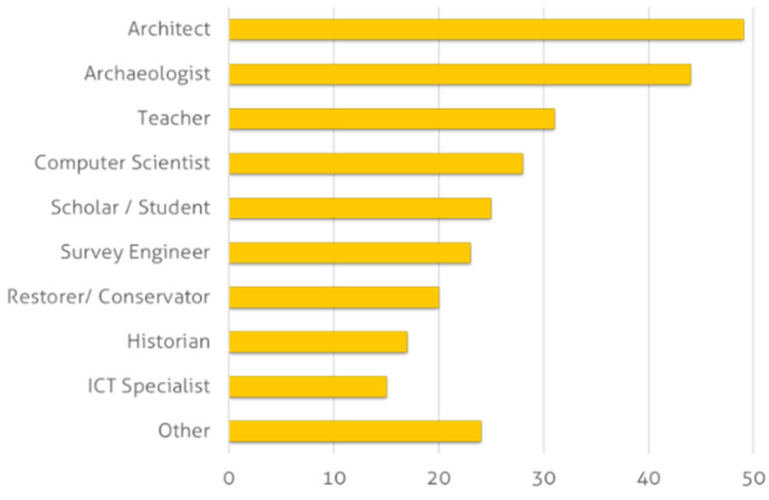

Figure 6: The graph reports the answers to the question "What is your professional background?

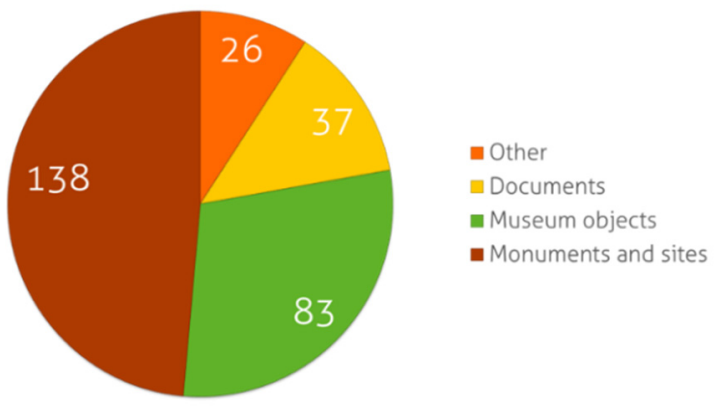

Figure 7: The graph reports the answer to the question "In which area of digitisation are you an expert?" $(n=296)$.

\section{Conclusion}

The Study consortium has collected data from different experts in digital cultural heritage regarding the significance and applications of quality and complexity in the 3D digitisation of tangible cultural heritage. The team will now focus on compiling this data and supplement it with the information coming from the online survey.

In parallel, the consortium has begun identifying existing formats, standards, benchmarks, methodologies, and guidelines relevant for 3D digitisation of tangible cultural heritage, including metadata and paradata (Task 3 ). The first results of these activities will be presented and discussed during the study's online mid-term workshop in March 2021.

\section{Acknowledgements}

Study at the request of and financed by the European Commission, Directorate-General of Communications Networks, Content \& Technology under contract no. LC01549024

\section{References}

Brumana, R., Banfi, F., Cantini, L., Previtali, M., \& Della Torre, S. (2019). HBIM level of detail-geometry-Accuracy and survey analysis for architectural preservation. ISPRS Annals of the Photogrammetry, Remote Sensing and Spatial Information Sciences, 42(2/W11), 293-299. Copernicus GmbH. https://doi.org/10.5194/isprs-Archives-XLII-2-W11293-2019

Brumana, R., Della Torre, S., Previtali, M., Barazzetti, L., Cantini, L., Oreni, D., \& Banfi, F. (2018). Generative HBIM modelling to embody complexity (LOD, LOG, LOA, LOI): surveying, preservation, site intervention-the Basilica di Collemaggio (L’Aquila). Applied Geomatics, 10(4), 545-567. https://doi.org/10.1007/s12518-018-0233-3

Cyprus University of Technology. (2020a). Home Page. Retrieved March 12, 2021, from https://www.cut.ac.cy/

Cyprus University of Technology. (2020b). Survey on quality in digitisation of tangible cultural heritage - LimeSurvey. Retrieved March 12, 2021, from https://web.cut.ac.cy/survey-expired/121155.html?lang=en

EuroMed. (2020). Workshops - EuroMed 2020. Retrieved March 12, 2021, from http://www.euromed2020.eu/workshops

European Commission. (2019). EU Member States sign up to cooperate on digitising cultural heritage. Retrieved March 12, 2021, from https://ec.europa.eu/digital-single-market/en/news/eu-member-states-sign-cooperate-digitisingcultural-heritage

European Commission. (2020a). Basic principles and tips for 3D digitisation of cultural heritage. Retrieved March 12, 2021, from https://ec.europa.eu/digital-single-market/en/news/basic-principles-and-tips-3d-digitisation-cultural-heritage

European Commission. (2020b). Study on quality in 3D digitisation of tangible cultural heritage. Retrieved March 12, 2021 , from https://ec.europa.eu/digital-single-market/en/news/study-quality-3d-digitisation-tangible-cultural-heritage

European Commission. (2020c). The European Commission launches a unique study on 3D digitisation of tangible cultural heritage. Retrieved March 12, 2021, from https://ec.europa.eu/digital-single-market/en/news/european-commissionlaunches-unique-study-3d-digitisation-tangible-cultural-heritage 
Europeana. (2020). Home Page. Retrieved March 12, 2021, from https://www.europeana.eu/en

Historic England. (2017). Photogrammetric Applications for Cultural Heritage. Retrieved March 12, 2021, from https://historicengland.org.uk/advice/technical-advice/recording-heritage/

Historic England. (2018). 3D Laser Scanning for Heritage. Retrieved March 12, 2021, from https://historicengland.org.uk/images-books/publications/3d-laser-scanning-heritage/

Historic Environment Scotland. (2018). Short Guide: Applied Digital Documentation in the Historic Environment. Retrieved March 12, 2021, from https://www.historicenvironment.scot/archives-andresearch/publications/publication/?publicationld=9b35b799-4221-46fa-80d6-a8a8009d802d 